Article

\title{
A Comparison Study of a Novel Self-Contained Electro-Hydraulic Cylinder versus a Conventional Valve-Controlled Actuator-Part 2: Energy Efficiency
}

\author{
Daniel Hagen * (D), Damiano Padovani ${ }^{(D)}$ and Martin Choux \\ Department of Engineering Sciences, University of Agder, 4879 Grimstad, Norway; \\ damiano.padovani@uia.no (D.P.); martin.choux@uia.no (M.C.) \\ * Correspondence: daniel.hagen@uia.no
}

Received: 18 November 2019; Accepted: 3 December 2019; Published: 5 December 2019

check for updates

\begin{abstract}
This research paper presents the second part of a comparative analysis of a novel self-contained electro-hydraulic cylinder with passive load-holding capability against a state of the art, valve-controlled hydraulic system that is typically used in load-carrying applications. After addressing the control design and motion performance in the first part of the study, the comparison is now focused on the systems' energy efficiency. It is experimentally shown that the self-contained solution enables $62 \%$ energy savings in a representative working cycle due to its throttleless and power-on-demand nature. In the self-contained drive, up to $77 \%$ of the energy taken from the power supply can be used effectively if the recovered energy is reused, an option that is not possible in the state of the art hydraulic architecture. In fact, more than $20 \%$ of the consumed energy may be recovered in the self-contained system during the proposed working cycle. In summary, the novel self-contained option is experimentally proven to be a valid alternative to conventional hydraulics for applications where passive load-holding is required both in terms of dynamic response and energy consumption. Introducing such self-sufficient and completely sealed devices also reduces the risk of oil spill pollution, helping fluid power to become a cleaner technology.
\end{abstract}

Keywords: linear actuators; self-contained cylinders; electro-hydraulic systems; passive load-holding; proportional directional control valves; load-carrying applications; energy recovery; energy efficiency

\section{Introduction}

Due to the increasing focus on the environmental impact, such as $\mathrm{CO}_{2}$ emissions and oil spill pollution, inefficient state of the art hydraulic actuation tends to be replaced by electric drives in many industrial environments. This is the case, for instance, in offshore oil drilling [1]. However, hydraulic systems are still needed in load-carrying applications (e.g., knuckle-boom cranes or oil drilling equipment) because their force density is higher than that of their linear electro-mechanical counterparts and they do not present key issues related to reliability (e.g., strong impact forces) [2].

Consequently, compact and self-contained electro-hydraulic cylinders (SCCs) have received considerable attention in the last decade [3-10], showing the potential to replace both conventional hydraulics and linear electro-mechanical systems [11]. SCCs can in fact enhance energy efficiency, modular design, plug-and-play installation, and reduced maintenance [12]. Current commercial solutions of the SCC technology are limited and typically tailor-made, whereas the research emphasis is primarily on different electro-hydraulic configurations [13-16], energy-efficiency [17-21], thermal analysis [22-24], and low-power servo applications [25]. According to the survey presented in [10], compact and self-contained solutions comprising passive load-holding devices, able to operate in four quadrants, and suitable for power levels above $5 \mathrm{~kW}$ are missing, both on the market and 
in the technical literature. Moreover, the lack of experimental comparisons in terms of energy consumption and efficiency between SCCs and conventional solutions for load-carrying applications is evident. Only a limited number of simulation studies applying the SCC technology to load-carrying applications and investigating the energy-saving potentials compared to existing hydraulic systems were identified $[26,27]$.

Hence, this research paper aims to experimentally evaluate and compare the energy consumption and the energy efficiency of a self-contained electro-hydraulic cylinder versus a conventional approach. A SCC concept able to operate in four quadrants, including passive load holding, and suitable for power levels above $5 \mathrm{~kW}$ was proposed in [10] and implemented on a single-boom crane in [12]. A further analysis of this solution is presented in the first part of this research [28], including the control design and the motion performance comparison against the valve-controlled cylinder (VCC) discussed in [29]. Concerning the paper structure, Section 2 presents the two considered actuation systems while Section 3 the theoretical background. In Section 4, the experimental results are introduced and discussed. The comparison study will show that the novel self-contained system is a valid alternative to conventional hydraulics also for applications where passive load-holding is required because huge energy savings are enabled.

\section{The Considered Actuation Systems}

Two actuation systems are investigated in this research, namely a new self-contained electro-hydraulic cylinder and state of the art valve-controlled architecture that is typically used on load-carrying applications.

\subsection{The Self-Contained Electro-Hydraulic Cylinder}

The combination of an electric drive and a fixed-displacement axial piston machine drives the hydraulic cylinder arranged in a closed-circuit configuration, as illustrated in Figure 1.

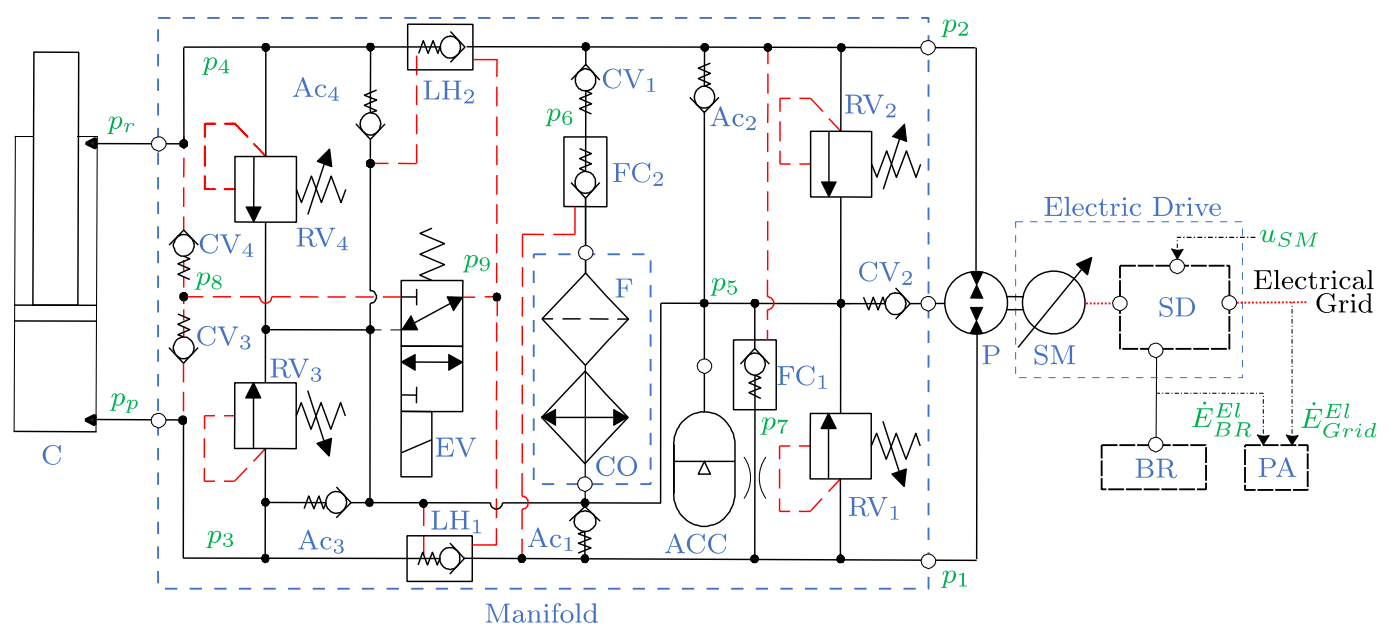

Figure 1. Schematic of the self-contained system addressed in this research.

The auxiliary hydraulic components are implemented in a manifold and the bladder-type accumulator represents the sealed reservoir. The differential flow dictated by the cylinder's unequal areas is balanced by the two pilot-operated check valves $F_{1}$ and $F_{2}$, the check valves $A_{1}$ and $A c_{2}$, and the check valve $\mathrm{CV}_{1}$. The pilot-operated check valves $\mathrm{LH}_{1}$ and $\mathrm{LH}_{2}$ are used for passive load-holding purposes by isolating the cylinder when the $3 / 2$ electro-valve is not actuated. The electro-valve must be activated to enable the actuator motion, resulting in transferring the highest cylinder pressure, selected through $\mathrm{CV}_{3}$ and $\mathrm{CV}_{4}$, into the opening pilot line of the load-holding valves. Anti-cavitation valves are installed on both actuator sides, whereas pressure-relief valves are present on the pump ports and 
on the cylinder ports to protect from over-pressurizations. Finally, a cooler and a low-pressure filter complete the hydraulic system.

The electric drive consists of the servo-motor and the servo-drive. The frequency converter is controlling the speed of the permanent magnet synchronous motor with field-oriented control whereas an outer closed-loop position controller is implemented on an embedded programmable logic controller (PLC) to supervise the motion of the hydraulic cylinder, sending the desired rotational speed $\left(u_{S M}\right)$ to the servo-drive. In addition, an external brake resistor is connected to the servo-drive to dissipate the regenerated power into heat. According to Ristic et al. [30], there exist solutions where this regenerated power is used profitably (e.g., power-sharing via common DC bus between multiple electric drives, return the electrical power to the grid, and energy storage on a battery or in a capacitor). Lastly, a power analyzer measures both the electric power consumed from the electrical grid $\left(\dot{E}_{G r i d}^{E l}\right)$ and the electric power dissipated in the brake resistor $\left(\dot{E}_{B R}^{E l}\right)$. For more details about the self-contained system, Padovani et al. [12] describes its functionality, while the components used to implement this solution are presented in Table 1.

Table 1. Components used to implement the self-contained system.

\begin{tabular}{|c|c|c|c|}
\hline Symbol & Component & Manufacturer & Model \\
\hline $\mathrm{C}$ & Hydraulic cylinder & PMC Cylinders ${ }^{1}$ & 25CAL \\
\hline SM & Servo-motor & Bosch Rexroth ${ }^{2}$ & MSK071E-0300 \\
\hline $\mathbf{P}$ & Axial piston machine & Bosch Rexroth & A10FZG \\
\hline SD & Servo-drive & Bosch Rexroth & HCS02.1E-W0054 \\
\hline $\mathrm{ACC}$ & Hydro-pneumatic accumulator & Bosch Rexroth & HAB10 \\
\hline $\mathrm{CO}$ & Oil cooler & Bosch Rexroth & KOL3N \\
\hline $\mathbf{F}$ & Hydraulic return line filter & Bosch Rexroth & 50LEN0100 \\
\hline $\mathbf{L H V}_{1,2}$ & Pilot-operated check valves & Sun Hydraulics ${ }^{3}$ & CVEVXFN \\
\hline $\mathbf{F C}_{1,2}$ & Pilot-operated check valves & Sun Hydraulics & CKEBXCN \\
\hline $\mathbf{R V}_{1-4}$ & Pressure-relief valves & Sun Hydraulics & RDDA \\
\hline $\mathbf{C V}_{1,3,4}$ & Check valves & Hawe Hydraulik 4 & RB2 \\
\hline $\mathbf{C V}_{2}, \mathbf{A c}_{1,2}$ & Check valves & Hawe Hydraulik & RK4 \\
\hline $\mathrm{Ac}_{3,4}$ & Check valves & Hawe Hydraulik & RK2 \\
\hline EV & 3/2 Directional valve & Argo Hytos 5 & SD1E-A3 \\
\hline$p_{1-9}$ & Pressure transducers & Bosch Rexroth & HM20 \\
\hline$p_{p, r}$ & Pressure transducers & Parker 6 & SCP-400 \\
\hline$x_{C}$ & Cylinder position sensor & Regal $^{7}$ & PS6300 \\
\hline PLC & Embedded controller & Bosch Rexroth & $\mathrm{XM} 22$ \\
\hline BR & Brake resistor & Bosch Rexroth & HLR01.1N-03K8 \\
\hline PA & Power analyzer & Hioki ${ }^{8}$ & PW6001 \\
\hline
\end{tabular}

${ }^{1}$ Sävsjö, Sweden; ${ }^{2}$ Lohr, Germany; ${ }^{3}$ Sarasota, USA; ${ }^{4}$ München, Germany; ${ }^{5}$ Zug, Switzerland; ${ }^{6}$ Cleveland, USA;

${ }^{7}$ Uppsala, Sweden; ${ }^{8}$ Nagano, Japan.

A hydraulic cylinder with piston diameter of $65 \mathrm{~mm}$, rod diameter of $35 \mathrm{~mm}$, stroke length of $500 \mathrm{~mm}$, and an integrated position sensor is common to both actuation systems (i.e., also to the valve-controlled layout recalled in the sequel). The piston's velocity $\left(\dot{x}_{C}\right)$ is estimated by differentiating and lowpass filtering the measured position $\left(x_{C}\right)$. Pressure transducers are installed directly on the piston-side $\left(p_{p}\right)$ and rod-side $\left(p_{r}\right)$ ports of the cylinder.

\subsection{The Valve-Controlled System}

The valve-controlled system taken as a benchmark consists of a centralized hydraulic power unit (HPU) providing a constant supply pressure $\left(p_{S}\right)$ and a fixed return pressure $\left(p_{R}\right)$ to the valve-controlled cylinder according to the schematic depicted in Figure 2. 


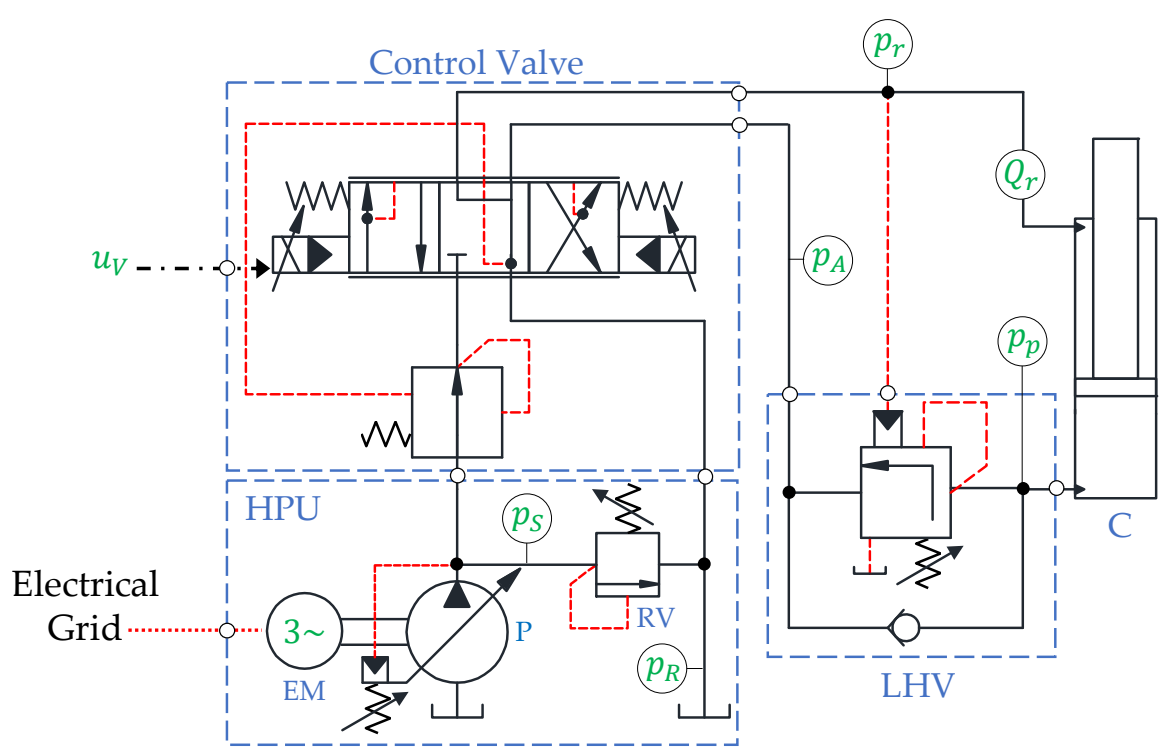

Figure 2. Schematics of the valve-controlled system under investigation.

The components of the HPU are an electric motor running at the constant speed of $1500 \mathrm{rpm}$ and a variable-displacement axial piston pump with a maximum displacement of $75 \mathrm{~cm}^{3} / \mathrm{rev}$. The supply pressure is controlled by the absolute pressure limiter as $p_{S}=180 \mathrm{bar}$, while a pressure-relief valve is installed for safety. The motion of the hydraulic cylinder is controlled by a state of the art, pressure-compensated flow control valve (i.e., a proportional directional control valve (PDCV)) that receives the control input $\left(u_{V}\right)$ from the PLC. The load-holding valve is installed to control overrunning loads and for safety purposes during standstill, according to regulations. Finally, the system is instrumented with sensors for measuring the pressures labeled in Figure 2 as well as the rod-side flow rate $\left(Q_{R}\right)$ and the piston position. For a more detailed description of the functionality of the valve-controlled cylinder, see for instance [29]. Details about the components implemented in the valve-controlled system are presented in Table 2.

Table 2. Components used to implement the valve-controlled system.

\begin{tabular}{cccc}
\hline Symbol & Component & Manufacturer & Model \\
\hline EM & Electric motor & ASEA & M225S60-4 \\
$\mathbf{P}$ & Axial piston variable pump & Brueninghaus Hydraulik $^{2}$ & A4V-S0-71 \\
RV & Pressure-relief valve & Bosch Rexroth & DBDH6 \\
V & Flow control valve & Sauer Danfoss & PVG32-9781 \\
LHV & Counterbalance valve & Sun Hydraulics & CWCA \\
$p_{S, R, A}$ & Pressure transducers & Parker & SCP-400 \\
$Q_{r}$ & Flow rate meter & Parker & SCQ-150 \\
\hline
\end{tabular}

${ }^{1}$ Västerås, Sweden; ${ }^{2}$ Horb, Germany; ${ }^{3}$ Nordborg, Denmark.

\section{Theoretical Background}

This section describes the analysis performed to process the experimental data collected from the two drive systems. The objective is highlighting the power levels, the energy consumption, and the efficiency of the architectures.

\subsection{Power and Energy Distribution}

The different power terms characteristic of both systems and highlighted in Figure 3 are evaluated using the equations presented below. For the sake of clarity, the input, the transferred, and the output powers are addressed in separate subsections. 


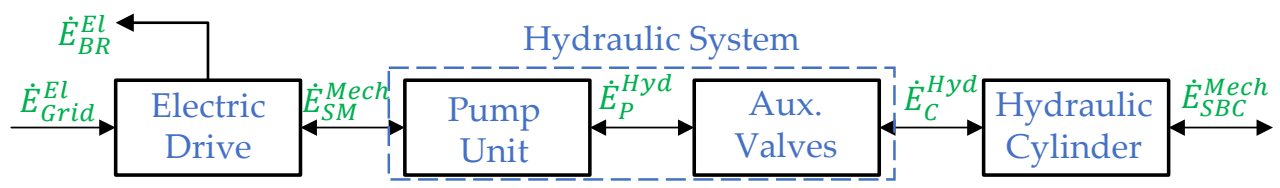

(a)

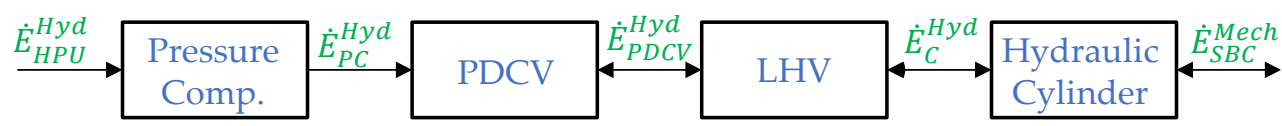

(b)

Figure 3. The different power terms: (a) Self-contained system; (b) valve-controlled system.

\subsubsection{Input Power}

The input power of the SCC corresponds to the electric power supplied by the electrical grid:

$$
\dot{E}_{G r i d}^{E l}=v_{a} \cdot i_{a}+v_{b} \cdot i_{b}+v_{c} \cdot i_{c}
$$

where $v_{i}$ and $i_{i}$ are the voltage and current of the $i$-th phase, respectively. Furthermore, when the external load is overrunning (i.e., when the cylinder is retracting), the SCC has the potential to regenerate power, while the VCC still consumes energy. For the test setup investigated in this study, the electric power regenerated by the SCC is dissipated in the brake resistor and is estimated according to:

$$
\dot{E}_{B R}^{E l}=v_{B R} \cdot i_{B R}
$$

where $v_{B R}$ is the pulse width modulated voltage, and $i_{B R}$ is the direct current, transferred from the servo-drive to the brake resistor. Hence, the combined input and output powers of the electric drive define the SCC's total electric power related to the power supply:

$$
\dot{E}_{P S}^{E l}=\dot{E}_{G r i d}^{E l}+\dot{E}_{B R}^{E l} \text {. }
$$

The VCC's input power is the hydraulic term calculated by involving the actuator's flow demand $\left(Q_{P}\right)$ and the supply pressure of the HPU:

$$
\dot{E}_{\mathrm{HPU}}^{H y d}=p_{S} \cdot\left|Q_{P}\right|,
$$

where the demand depends on the valve command $\left(u_{V}\right)$, the measured flow rate $\left(Q_{r}\right)$, and the areas of the actuator according to the following logic:

$$
Q_{P}=\left\{\begin{array}{rr}
Q_{r} \cdot \frac{A_{p}}{A_{r},} & u_{V}<0 \\
0, & u_{V}=0 \\
Q_{r}, & u_{V}>0
\end{array}\right.
$$

\subsubsection{Transferred Power Losses}

The mechanical power transferred between the SCC's servo-motor and the axial piston machine:

$$
\dot{E}_{S M}^{M e c h}=i_{q} \cdot k_{t} \cdot \omega_{S M}
$$

is described by the torque-producing current component $\left(i_{q}\right)$, the torque constant $\left(k_{t}=2.05 \mathrm{Nm} / \mathrm{A}\right)$, and the measured rotational speed $\left(\omega_{S M}\right)$ of the prime mover. The hydraulic power shared between 
the hydraulic machine and the manifold is defined by involving the effective flow supplied to the actuator and the pressure drop across the unit:

$$
\dot{E}_{P}^{H y d}=\dot{x}_{C} \cdot A_{p} \cdot\left(p_{1}-p_{2}\right) .
$$

Then, the hydraulic power distributed between the manifold and the cylinder results as:

$$
\dot{E}_{C}^{H y d}=\dot{x}_{C} \cdot\left(A_{p} \cdot p_{p}-A_{r} \cdot p_{r}\right) .
$$

The power losses of the SCC take place in the electric drive (i.e., electric and mechanical losses), in the axial piston machine (i.e., mechanical-hydraulic and volumetric losses), in the auxiliary components (i.e., reduced throttling losses in the check valves), and in the hydraulic cylinder (i.e., friction losses and internal leakage).

Concerning the VCC's, the hydraulic power available downstream the pressure compensator is calculated based on the valve command as:

$$
\dot{E}_{P C}^{H y d}=\left\{\begin{aligned}
\left(p_{p}+p_{0}\right) \cdot\left|Q_{P}\right|, & u_{V}<0 \\
0, & u_{V}=0, \\
\left(p_{r}+p_{0}\right) \cdot\left|Q_{P}\right|, & u_{V}>0
\end{aligned}\right.
$$

including the fixed pressure-drop across the control valve's metering edge $\left(p_{0}\right)$. Further on, the hydraulic power delivered by the control valve is again function of $u_{V}$ :

$$
\dot{E}_{P D C V}^{H y d}=\left\{\begin{aligned}
p_{p} \cdot Q_{P}, & u_{V}<0 \\
0, & u_{V}=0 . \\
p_{r} \cdot Q_{P}, & u_{V}>0
\end{aligned}\right.
$$

Then, the hydraulic power related to the hydraulic cylinder results as described in Equation (8). The power losses taking place in the VCC are the throttling losses of the pressure compensator, the throttling losses of the control valve's spools, the throttling losses in the counterbalance valve, and the friction losses and internal leakages of the hydraulic cylinder. Finally, the losses of the HPU are neglected in this experimental study to be conservative, since it is sized for delivering constant pressure to several applications available in the lab.

\subsubsection{Output Power}

When actuating the considered single-boom crane depicted in Figure 4a, the mechanical output power that is applicable to both systems, is defined as:

$$
\dot{E}_{S B C}^{M e c h}=\frac{d}{d t} \cdot\left(E_{K}+E_{P}\right),
$$

where $E_{K}$ and $E_{P}$ are the kinetic and potential energy, obtained according to Equations (12) and (13).

The diagram shown in Figure $4 \mathrm{~b}$ identifies the parameters used in the calculation of the total mechanical energy. Relevant numerical values describing the kinematics are listed in Table 3. 


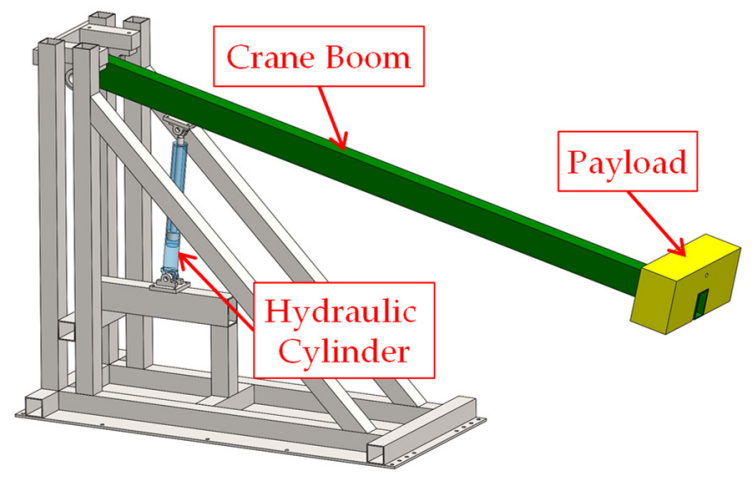

(a)

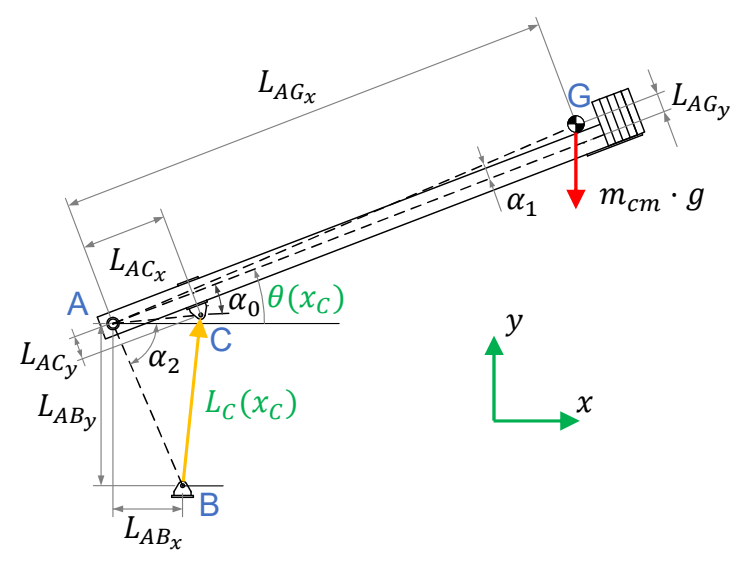

(b)

Figure 4. The considered application: (a) The hydraulic actuator connected to the crane-boom; (b) simplified schematic diagram of the crane's kinematics.

Table 3. Kinematic parameters of the single-boom crane with full payload.

\begin{tabular}{cccc}
\hline Parameter & Value & Parameter & Value \\
\hline$m_{c m}$ & $415.08(\mathrm{~kg})$ & $L_{A B}$ & $1136(\mathrm{~mm})$ \\
$J_{c m}$ & $159.63\left(\mathrm{~kg} \cdot \mathrm{m}^{2}\right)$ & $\alpha_{0}$ & $0.232(\mathrm{rad})$ \\
$L_{A G x}$ & $3139(\mathrm{~mm})$ & $\alpha_{1}$ & $0.020(\mathrm{rad})$ \\
$L_{A G y}$ & $64(\mathrm{~mm})$ & $\alpha_{2}$ & $1.192(\mathrm{rad})$ \\
$L_{A C}$ & $565(\mathrm{~mm})$ & $g$ & $9.81\left(\mathrm{~m} / \mathrm{s}^{2}\right)$ \\
\hline
\end{tabular}

The kinetic energy and the potential energy, as a function of the angular speed $(\dot{\theta})$ and angular position $(\theta)$ of the boom, are defined according to the following equations:

$$
\begin{gathered}
E_{K}(\dot{\theta})=\frac{1}{2} \cdot\left(m_{c m} \cdot L_{A G x}^{2}+m_{c m} \cdot L_{A G y}^{2}+J_{c m}\right) \cdot \dot{\theta}^{2}, \\
E_{P}(\theta)=m_{c m} \cdot g \cdot\left(L_{A G y} \cdot \cos \left(\theta+\alpha_{1}\right)+L_{A G x} \cdot \sin \left(\theta+\alpha_{1}\right)\right),
\end{gathered}
$$

where the angular position of the boom and the effective length of the hydraulic cylinder $\left(L_{C}\right)$, including the initial length $\left(L_{C, 0}=772 \mathrm{~mm}\right)$, are given below as a function of the piston position:

$$
\begin{gathered}
\theta\left(x_{C}\right)=\cos ^{-1}\left(\frac{L_{A C}^{2}+L_{A B}^{2}-L_{C}^{2}\left(x_{C}\right)}{2 \cdot L_{A C} \cdot L_{A B}}\right)-\alpha_{2}+\alpha_{0}, \\
L_{C}\left(x_{C}\right)=x_{C}+L_{C, 0} .
\end{gathered}
$$

\subsection{Efficiency of the Systems}

Starting from the SCC, the overall efficiency $\left(\eta_{\text {Overall }}\right)$, the efficiency of the electric drive $\left(\eta_{E D}\right)$, and the efficiency of the hydraulic sub-system $\left(\eta_{H S}\right)$ are given in Equations (16)-(18). Due to the dual behavior of the system being regenerative while retracting the cylinder (i.e., the load is overrunning when the crane boom is lowered), and consuming when extending the cylinder (i.e., the load is resistant when the crane boom is lifted), two alternatives are introduced in the following definitions:

$$
\eta_{\text {Overall }}^{S C C}=\left\{\begin{array}{ll}
\frac{\dot{E}_{P S}^{E l}}{\dot{E}_{S S C h}}, & \dot{E}_{P S}^{E l}>0 \text { (resistant load) } \\
\frac{\dot{E}_{S B C h}^{\text {Mech }}}{\dot{E}_{P S}^{E l}}, & \dot{E}_{P S}^{E l} \leq 0 \text { (overrunning load) }
\end{array},\right.
$$




$$
\begin{aligned}
& \eta_{E D}^{S C C}=\left\{\begin{array}{ll}
\frac{\dot{E}_{P S}^{E l}}{\dot{E}_{S M}^{M c h},} & \left.\dot{E}_{P S}^{E l}>0 \text { (resistant load }\right) \\
\frac{\dot{E}_{S M}^{\text {Mech }}}{\dot{E}_{P S}^{E l}}, & \dot{E} E_{P S} \leq 0 \text { (overrunning load) }
\end{array},\right. \\
& \eta_{H S}^{S C C}= \begin{cases}\frac{\dot{E}_{S M}^{\text {Mech }}}{\dot{E}_{\mathcal{H}}}, & \left.\dot{E}_{S M}^{\text {Mech }}>0 \text { (resistant load }\right) \\
\dot{E}_{C \text { d d }} & \left.\dot{E}_{S M}^{\text {Mech }} \leq 0 \text { (overrunning load }\right) \\
\frac{\dot{E}_{C} \text { Mech }}{\dot{E}_{S M}} & E_{S M}\end{cases}
\end{aligned}
$$

Similar terms are also proposed for the VCC, where the efficiency of the control valve $\left(\eta_{V}\right)$ and of the remaining hydraulic system, namely the load-holding valve $\left(\eta_{L H V}\right)$, are given as follows:

$$
\begin{aligned}
& \eta_{\text {Overall }}^{V C C}=\left\{\begin{array}{rl}
\frac{\dot{E}_{H P U}^{H y d},}{\dot{E}_{S B C}^{M e c h}} & \dot{E}_{H P U}^{H y d}>0 \text { (resistant load) } \\
0, & \dot{E}_{H P U}^{H y d} \leq 0 \text { (overrunning load) }
\end{array},\right. \\
& \eta_{V}^{V C C}=\left\{\begin{array}{rl}
\frac{\dot{E}_{H P U}^{H y d}}{\dot{E}_{P D C V}^{H y d}}, & \dot{E}_{H P U}^{H y d}>0(\text { resistant load) } \\
0, & \dot{E}_{H P U}^{H y d} \leq 0 \text { (overrunning load) }
\end{array},\right. \\
& \eta_{L H V}^{V C C}=\left\{\begin{array}{ll}
\frac{\dot{E}_{P D D C}^{H y d}}{\dot{E}_{C}^{H y d}}, & \dot{E}_{P D C V}^{H y d}>0 \text { (resistant load) } \\
\frac{\dot{E}_{C}^{H y d}}{\dot{E}_{H y d}}, & \dot{E}_{P D C V}^{H y d} \leq 0 \text { (overrunning load) }
\end{array} .\right.
\end{aligned}
$$

\section{Experimental Results and Discussion}

After mentioning the experimental test-beds, the considered working cycle is addressed. Then, the power levels and efficiencies of the different sub-systems are separately evaluated while lifting and lowering the single-boom crane. Finally, the overall energy consumption and efficiency are assessed. The experimental data were collected by using the test setups illustrated in Figure 5.

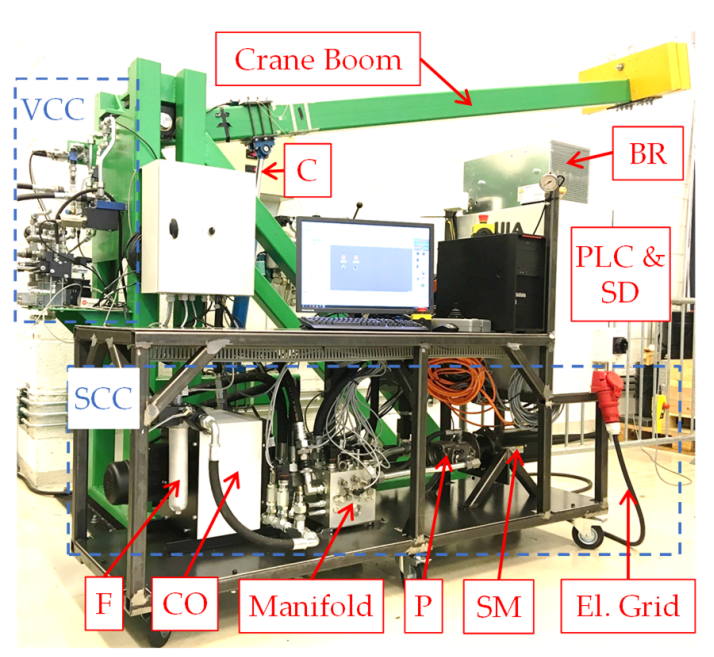

(a)

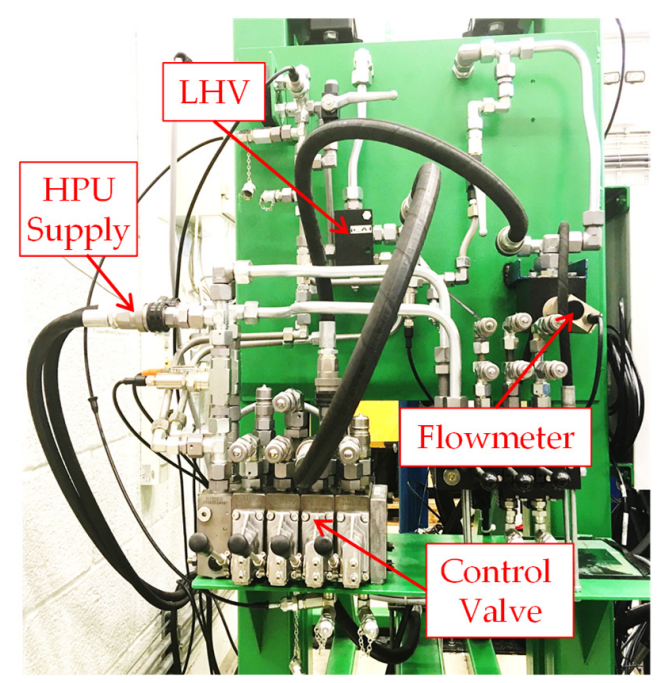

(b)

Figure 5. The experimental setups: (a) The self-contained electro-hydraulic system; (b) a portion of the valve-controlled system. 
All data, besides the electric power, is processed through a real-time interface (i.e., $1 \mathrm{~ms}$ sample rate) between the PLC and MATLAB-Simulink ${ }^{\circledR}$. The measured electric power is collected with a $50 \mathrm{~ms}$ sample rate and further processed in the MATLAB-Simulink ${ }^{\circledR}$ environment. Mineral oil ISO VG 46 is used as the hydraulic fluid in both actuation systems. All tests were carried out for a working cycle with maximum payload (i.e., with a load mass equal to $304 \mathrm{~kg}$ ). The motion profile generator, presented in [27], provides reference signals for the desired piston position and velocity, as illustrated in Figure 6. The cylinder's piston extends and retracts between the start position $x_{C, 0}=50 \mathrm{~mm}$ and the desired position $x_{C, r e f}=450 \mathrm{~mm}$, at a desired maximum velocity $v_{C, \max }=120 \mathrm{~mm} / \mathrm{s}$.

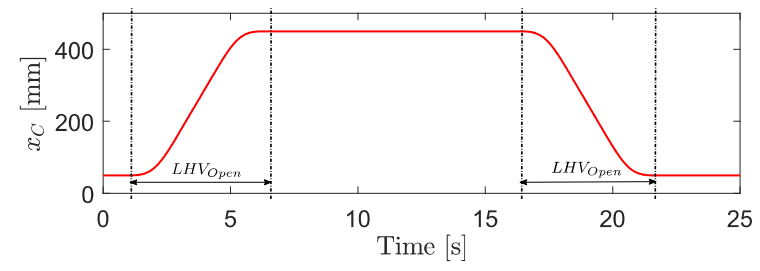

(a)

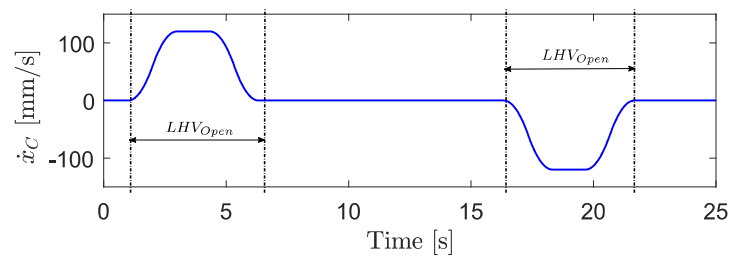

(b)

Figure 6. Generated motion profile: (a) Desired piston position; (b) desired piston velocity.

The SCC is operated in closed-loop, including position feedback control, velocity feedforward, pressure feedback, and passive load-holding, according to the control strategy and the control algorithm presented in the first part of this comparison study [28]. In passive load-holding mode, the load-holding valves are closed by deactivating the electro-valve and switching off the signal enabling power to the prime mover when motion is not desired.

\subsection{Power Levels}

The power levels of the different terms mentioned in Section 3.1 are shown in Figure 7.

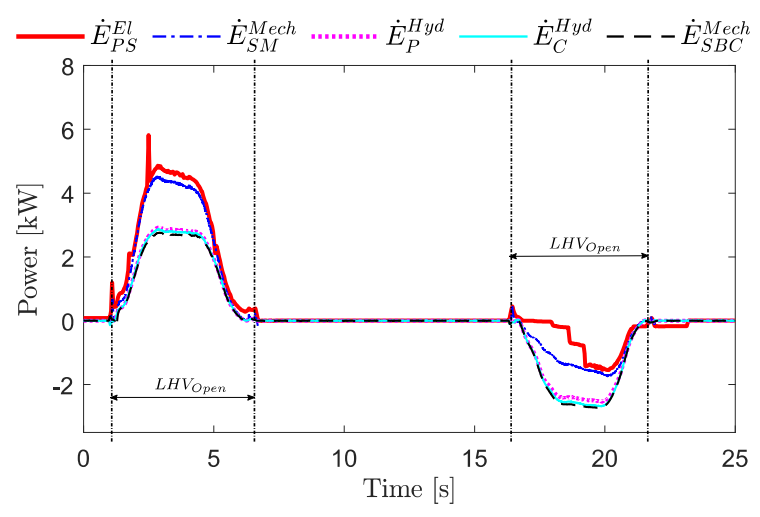

(a)

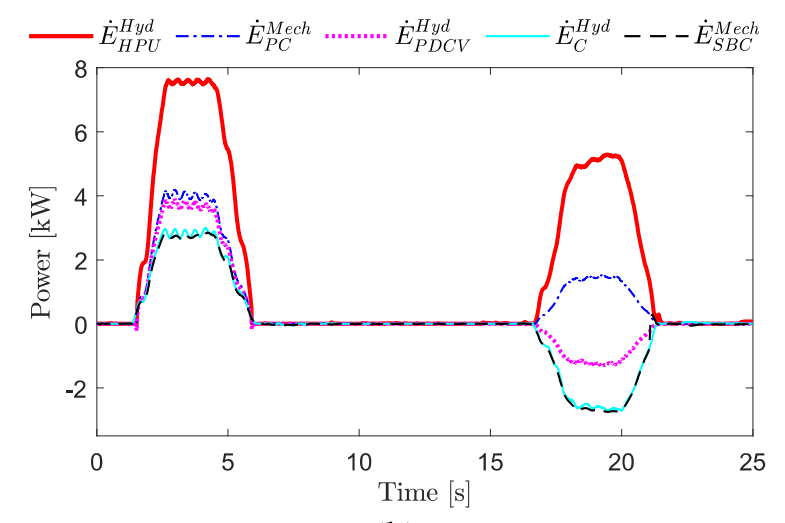

(b)

Figure 7. Power measurements: (a) Self-contained system; (b) valve-controlled system.

When the values in Figure 7 are positive, then the power is transferred to the actuator. Vice versa (i.e., when the trends are negative), there is potential to recover energy. During the crane's lowering phase, the SCC outputs electrical power, while the VCC dissipates hydraulic energy in the valves. It is worth mentioning that, during steady-state operations, the VCC requires a maximum power of about $7.6 \mathrm{~kW}$ while the SCC demands only $4.8 \mathrm{~kW}$ (37\% less).

\subsection{Systems Efficiency}

The overall efficiency of both systems is plotted in Figure 8 together with the terms related to the different sub-systems. 


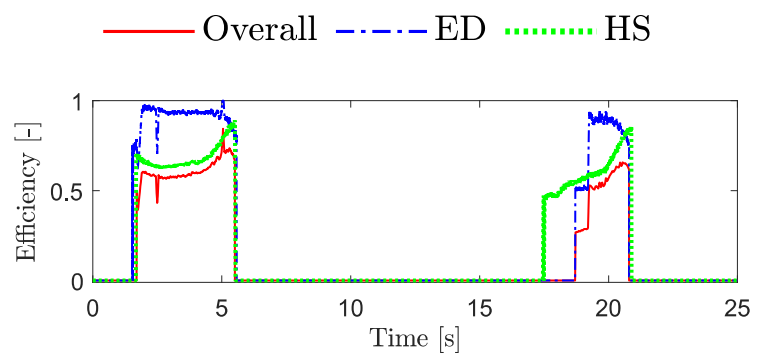

(a)

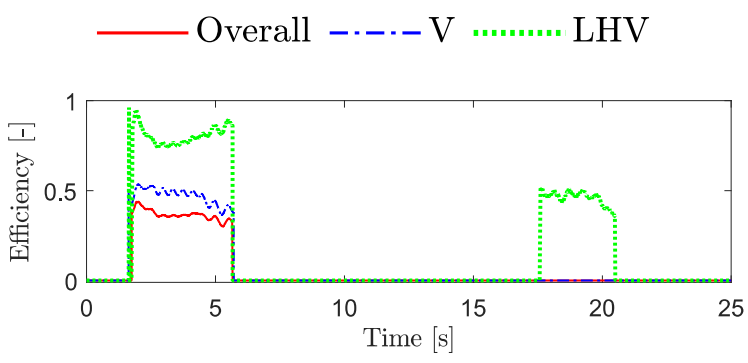

(b)

Figure 8. Efficiency of the systems: (a) Self-contained system; (b) valve-controlled system.

The results in Figure 8a show that the SCC's efficiency, when the cylinder is lifting the crane at steady-state (i.e., at $4 \mathrm{~s}$ ) is about $60 \%$ for the overall system, $93 \%$ for the electric drive, and $65 \%$ for the hydraulics. The overall efficiency when lowering the crane boom, assuming full recovery of the regenerated power, varies at $51-65 \%$. It can be observed in Figure $8 \mathrm{a}$ that there is a $1.2 \mathrm{~s}$ delay between when the SCC starts to lower the crane boom, and the electric drive starts to regenerate power. For the benchmark system (Figure $8 \mathrm{~b}$ ), the overall efficiency is $36 \%$ when the cylinder is lifting the crane boom at steady-state (i.e., at 4 s). Furthermore, almost $50 \%$ of the VCC's input power is dissipated in the control valve (the most in the pressure-compensator). The efficiency of the counterbalance valve, during lifting (i.e., the flow is bypassed through the LHV's check valve), is $74 \%$ at the lowest, and at the maximum $51 \%$ through the lowering phase (i.e., the LHV's poppet introduces a desired pressure-drop).

\subsection{Energy Consumption}

As described in the first part of this study [28], the SCC can be operated with two different load-holding strategies, namely passive load-holding (PLH) and active load-holding (ALH). The electric power and energy consumption when utilizing these two strategies are compared in Figure 9.

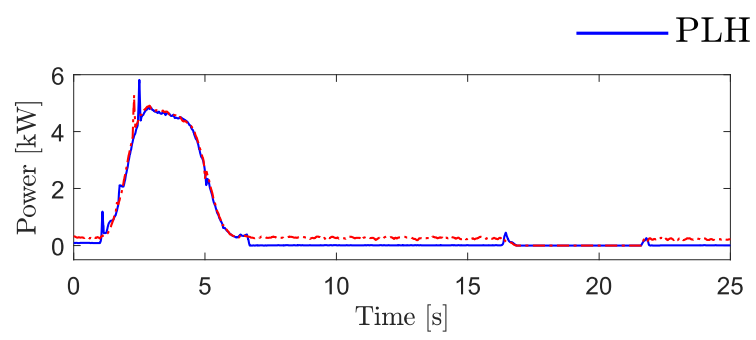

(a)

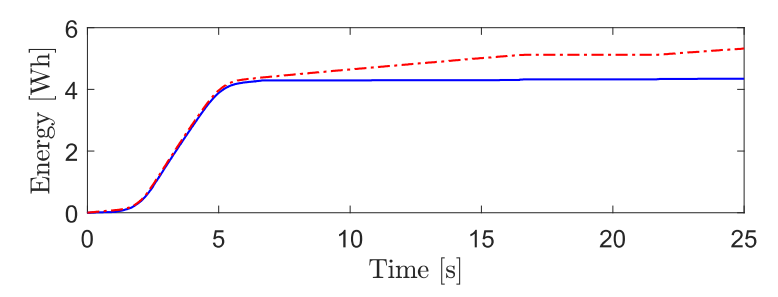

(b)

Figure 9. Comparison between passive and active load-holding for the self-contained cylinder: (a) Input power; (b) energy consumption.

When the SCC maintains the desired piston position between 6.5 and $16 \mathrm{~s}$ (Figure 9a), the measured electric input power varies at 5-7 W with passive load-holding, and at 187-312 W with active load-holding. Active load-holding results in an energy consumption of $5.32 \mathrm{Wh}$ for the entire working cycle considered here (Figure $9 \mathrm{~b}$ ), compared to $4.34 \mathrm{Wh}$ with passive load-holding (i.e., $18.4 \%$ less). However, performing active load-holding for a reduced amount of time is still acceptable since the power consumption remains relatively low.

Moving to the valve-controlled layout, load-sensing pumps are used instead of constant-pressure supplies to increase the overall efficiency in many applications. Two scenarios are therefore addressed; the first one (Figure 10a) focuses on measurements from the test setup. The scenario \#2 (Figure 10b) considers an HPU equipped with a load-sensing pump and driven by an induction motor running at $1500 \mathrm{rpm}$ (the losses of the HPU are simulated based on the model presented in [27]). Full energy 
recovery is then assumed for the SCC in this second situation (i.e., the energy dissipated in the brake resistor when the SCC is lowering the crane boom is now reused).

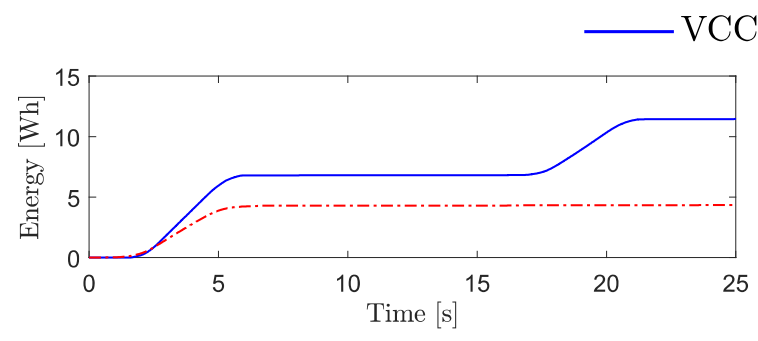

(a)

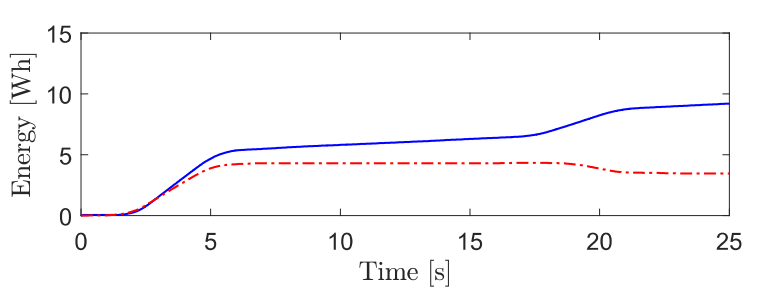

(b)

Figure 10. Energy consumption comparison: (a) The scenario \#1; (b) the scenario \#2.

The results in Figure 10a show that the SCC does not consume any energy when lowering the load, resulting in $62.1 \%$ less consumption compared to the 11.44 Wh of the VCC. This improvement is expected since the VCC needs to build up pressure to enable flow through the counterbalance valve that introduces functional losses, while the SCC uses the highest actuator pressure to fully open the two load-holding valves. For scenario \#2 (Figure 10b), the VCC consumes energy also when the cylinder is not moving because the electric-motor is continuously running; due to the load-sensing unit, then $19.6 \%$ less energy is taken compared to the VCC in scenario \#1. When comparing the two systems in scenario \#2, the SCC still consumes less energy than the VCC (62.4\% less); this behavior favorable to the SCC is also the case when there is no useful usage of the recovered energy.

\subsection{Energy Distribution}

The energy distribution between the main components of the two systems, initially monitored when the cylinder is lifting the crane boom, is illustrated in Figure 11.

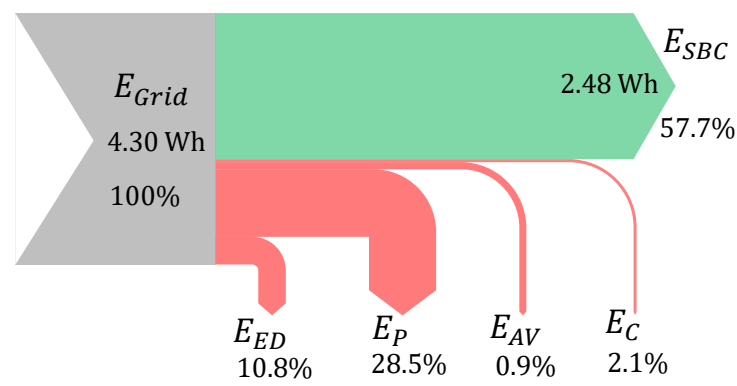

(a)

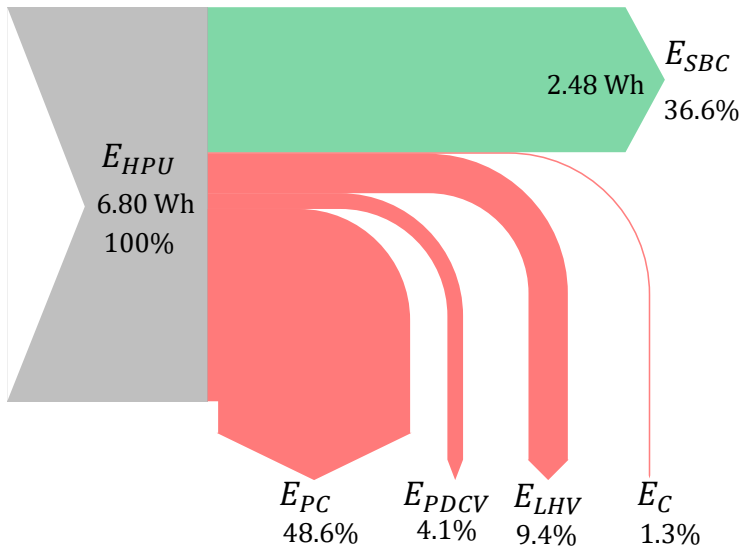

(b)

Figure 11. The energy distribution when lifting the crane boom: (a) Self-contained system; (b) valve-controlled system.

The complete energy conversion from the source (i.e., the electric grid for the SCC and the hydraulic power supply for the VCC) to the end user (i.e., the payload of the crane) is handled. The total amount of energy being lost in the SCC is $42.3 \%$, while it increases up to $63.4 \%$ in the VCC (this is a conservative estimation because the losses of the HPU are neglected). It should be noted that all losses in the SCC are parasitic, with the pump being the predominant source followed by the electric motor. This aspect does not hold true for the VCC since the compensator introduces a relevant dissipation that is functional (this term could be reduced for higher loads, or when using a 
load-sensing power supply). Moreover, only the SCC has the potential to recover energy; Figure 12 illustrates the energy distribution in the SCC when the crane boom is lowered.

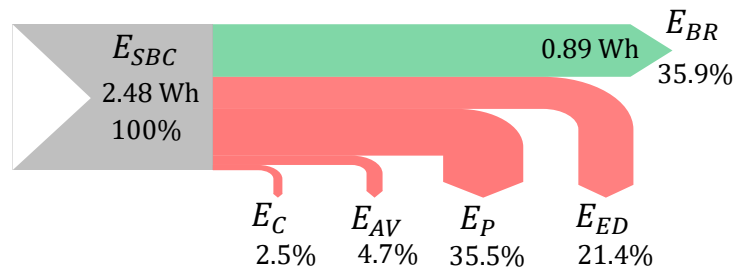

Figure 12. The energy distribution of the self-contained system when lowering the crane boom.

A significant portion (35.9\%) of the energy delivered by the load that is lowered can be outputted by the electric drive; it is worth noticing that this quantity is completely lost in the valve-controlled architecture. In particular, the total energy being dissipated in the SCC during piston retraction $(64.1 \%$ of the input) is mainly due to the losses in the axial piston machine and in the electric drive.

Finally, the energy distribution during a complete working cycle is depicted in Figure 13 for both the SCC and the VCC, where the energy taken from the grid is now considered also for the VCC (i.e., scenario \#2 with the power supply equipped with a load-sensing pump).

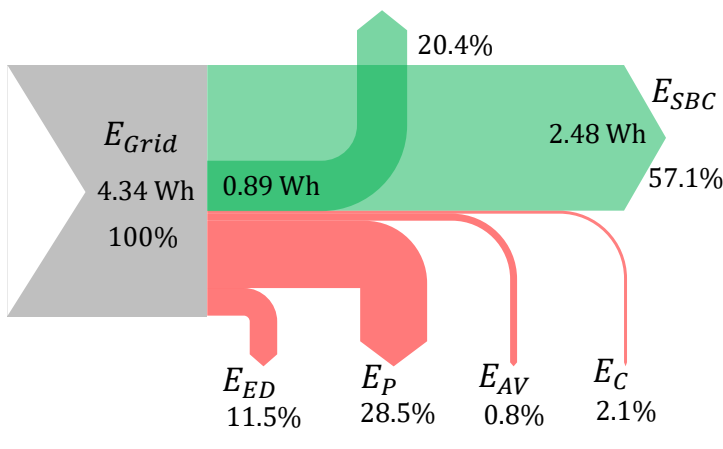

(a)

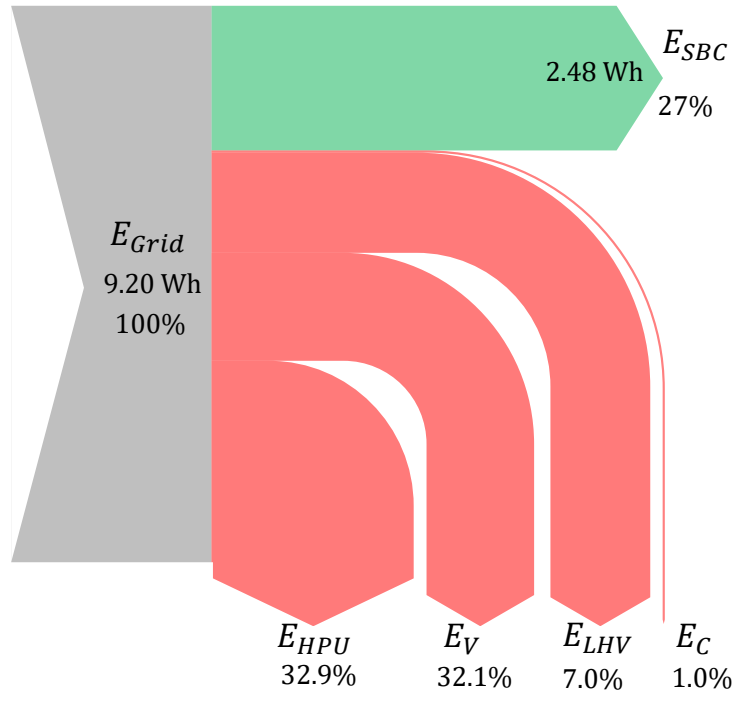

(b)

Figure 13. The energy distribution during a complete working cycle: (a) Novel self-contained system; (b) valve-controlled system when simulating a load-sensing pump and hydraulic power unit losses.

The results show that $57.1 \%$ of the input energy is transferred to the load for the SCC and $27 \%$ for the VCC. Figure 13a reveals that the SCC may recover 20.4\% of the electrical energy taken from the grid during a complete working cycle. Assuming a realistic $94 \%$ conversion efficiency to return the recovered energy to the grid, then $76.5 \%$ of the total energy taken from the source can be used effectively. Further on, when considering a VCC supplied by a load-sensing pump (Figure 13b), the efficiency increases due to the major reduction of the functional losses in the control valve $\left(E_{V}\right)$. However, including also the inefficiencies of the HPU (i.e., the losses of the electric motor and of the pump), the overall efficiency is only increased by 5.3\% compared to the VCC supplied with constant pressure supply (scenario \#1) that is characterized by an overall energy efficiency of $21.7 \%$.

\section{Conclusions}

This research paper experimentally compares a novel self-contained electro-hydraulic cylinder and a hydraulic, valve-controlled, linear actuator representative of the state of the art in many fields of 
industry. A single-boom crane requiring passive load-holding is taken as the reference application, while the emphasis of the study is placed on the energy efficiency of the drives. The results show that the electro-hydraulic layout reduces the energy consumption significantly (up to $62 \%$ less) due to its throttleless nature and power-on-demand functioning. More specifically, the following aspects emerge from the study:

- The power demand to the prime mover during steady-state operations reduces to $4.8 \mathrm{~kW}$ against the $7.6 \mathrm{~kW}$ in the valve-controlled system ( $37 \%$ less) throughout the investigated working cycle;

- Utilizing passive load-holding results in an energy saving of $18.4 \%$ compared to actively controlling the SCC's desired position using the prime mover during load holding phases;

- The system's overall efficiency of the self-contained drive, being approximately $57 \%$ during actuation, turns out to be highly satisfactory compared to the $22 \%$ efficiency of the valve-controlled system with a constant-pressure supply;

- A significant amount of energy (i.e., $20 \%$ of the consumed energy) is recovered by the self-contained solution during the proposed working cycle. Hence, when assuming a realistic $94 \%$ conversion efficiency to return the recovered energy to the grid, then $77 \%$ of the total energy taken from the source can be used effectively. In contrast, this efficient operation is not possible in the valve-controlled system where, rather than being recovered, the available energy is dissipated when the load acting on the actuator is overrunning;

- An alternative scenario based on the load-sensing concept is also considered for the valve-controlled system; its energy consumption reduces from 11.44 Wh to $9.20 \mathrm{Wh}$ but remains inefficient with respect to the electro-hydraulic actuator (i.e., total consumption $4.34 \mathrm{Wh}$ ).

Recalling the positive outcomes about motion control obtained in the first part of the research and disseminated in a different article, it is therefore concluded that the novel energy-efficient, self-contained drive represents a valid alternative to conventional hydraulic systems for load-carrying applications. Introducing a self-sufficient and completely sealed device also reduces the risk of oil spill pollution, helping fluid power to become a cleaner technology. Concerning future developments about the self-contained system, effort will be placed on both optimizing the sizing procedure to maximize energy efficiency as well as on designing and testing advanced solutions that reuse the recovered energy.

Author Contributions: Conceptualization, D.H. and D.P.; methodology, D.H.; software, D.H.; validation, D.H.; formal analysis, D.H.; investigation, D.H.; data curation, D.H.; writing-original draft preparation, D.H.; writing—review and editing, D.H., D.P., and M.C.; visualization, D.H.; supervision, D.P. and M.C.

Funding: This research was funded by the Norwegian Research Council, SFI Offshore Mechatronics, project 237896.

Conflicts of Interest: The authors declare no conflict of interest.

\section{Nomenclature}

$\begin{array}{ll}\text { Abbreviations } \\ \text { AC } & \text { Alternating current } \\ \text { ACC } & \text { Accumulator } \\ \text { Ac } & \text { Anti-cavitation valve } \\ \text { ALH } & \text { Active load-holding } \\ \text { AV } & \text { Auxiliary valves } \\ \text { BR } & \text { Brake resistor } \\ \text { C } & \text { Hydraulic cylinder } \\ \text { CO } & \text { Oil cooler } \\ \text { CV } & \text { Check valve } \\ \text { DC } & \text { Direct current } \\ \text { ED } & \text { Electric drive } \\ \text { EM } & \text { Electric motor } \\ \text { EV } & \text { Electro-valve }\end{array}$


F Low pressure oil filter

FC Flow compensation valve

HPU Hydraulic power unit

HS Hydraulic system

LHV Load-holding valve

P Axial piston machine (pump)

PDCV Proportional directional control valve

PLC Programmable logic controller

RV Pressure-relief valve

SBC Single-boom crane

SCC Self-contained electro-hydraulic cylinder

SD Servo-drive

SM Servo-motor

$\mathrm{V} \quad$ Control valve

VCC Valve-controlled cylinder

Symbols

$A_{p} \quad$ Cylinder area on the piston-side

$A_{r} \quad$ Cylinder area on the rod-side

$E_{K} \quad$ Kinetic energy

$E_{P} \quad$ Potential energy

E Energy

$\dot{E} \quad$ Power

$i_{a}, i_{b}, i_{c} \quad$ Three-phase current of the electric power supply

$i_{B R} \quad$ Direct current of the brake resistor

$i_{q} \quad$ Torque-producing current component

$J_{c m} \quad$ Inertia at center of mass

$k_{t} \quad$ Torque constant

$L_{A B} \quad$ Length between joint A and B

$L_{A C} \quad$ Length between joint $A$ and $C$

$L_{A G x} \quad$ Length between joint $A$ and $G$ in $x$-direction

$L_{A G y} \quad$ Length between joint $A$ and $G$ in y-direction

$L_{C, 0} \quad$ Length of the hydraulic cylinder when fully retracted

$L_{C} \quad$ Effective total length of the hydraulic cylinder

$m_{c m} \quad$ Mass at center of mass

$\omega_{S M} \quad$ Rotational speed of the servo-motor in radians per seconds

$Q_{P} \quad$ Actuator's flow demand

$Q_{r} \quad$ Rod-side flow rate

$p_{0} \quad$ Fixed pressure-drop across the proportional directional control valve

$p_{1} \quad$ Pressure at the pump/motor port on the piston-side of the actuator

$p_{2} \quad$ Pressure at the pump/motor port on the rod-side of the actuator

$p_{p} \quad$ Actuator's piston chamber pressure

$p_{r} \quad$ Actuator's rod chamber pressure

$p_{R} \quad$ Return pressure

$p_{S} \quad$ Supply pressure

$u_{S M} \quad$ Commanded servo-motor speed

$u_{V} \quad$ Commanded opening of the control valve's spool position

$v_{a}, v_{b}, v_{c} \quad$ Three-phase voltage of the electric power supply

$v_{B R} \quad$ Direct current voltage of the brake resistor

$x_{C} \quad$ Actuator's piston position

$\dot{x}_{C} \quad$ Actuator's piston velocity

\section{Greek Symbols}

$\alpha_{i} \quad$ Arctangent of the xy-length between the $i$-th joints

$\eta_{i} \quad$ Efficiency of the $i$-th system

$\theta \quad$ Angular position of the boom 


\section{References}

1. Pawlus, W.; Choux, M.; Hansen, M.R. Hydraulic vs. electric: A review of actuation systems in offshore drilling equipment. Model. Identif. Control 2016, 37, 1-17. [CrossRef]

2. Hagen, D.; Pawlus, W.; Ebbesen, M.K.; Andersen, T.O. Feasibility Study of Electromechanical Cylinder Drivetrain for Offshore Mechatronic Systems. Model. Identif. Control 2017, 38, 59-77. [CrossRef]

3. Michel, S.; Weber, J. Electrohydraulic Compact-Drives for Low Power Applications Considering Energy-efficiency and High Inertial Loads. In Proceedings of the 7th FPNI PhD Symposium on Fluid Power, Reggio Emilia, Italy, 27-30 June 2012; pp. 27-30.

4. Minav, T.A.; Sainio, P.; Pietola, M. Direct Driven Hydraulic Drive without Conventional Oil Tank. In Proceedings of the ASME/BATH 2014 Symposium on Fluid Power and Motion Control, Bath, UK, 10-12 September 2014.

5. Altare, G.; Vacca, A.; Richter, C. A Novel Pump Design for an Efficient and Compact Electro-Hydraulic Actuator. In Proceedings of the IEEE Aerospace Conference, Big Sky, MT, USA, 1-8 March 2014.

6. Altare, G.; Vacca, A. A design solution for efficient and compact electro-hydraulic actuators. Procedia Eng. 2015, 106, 8-16. [CrossRef]

7. Rexroth, B. Electrification and Digitalization: The Fitness Program for Hydraulics. 2015. Available online: https://www.boschrexroth.com/en/xc/products/product-groups/industrial-hydraulics/thefitness-program-for-hydraulics (accessed on 21 September 2019).

8. Helbig, A.; Boes, C. Electric Hydrostatic Actuation-Modular Building Blocks for Industrial Applications. In Proceedings of the 10th International Fluid Power Conference, Dresden, Germany, 8-10 March 2016; pp. 93-102.

9. Pedersen, H.C.; Schmidt, L.; Andersen, T.O.; Brask, M.H. Investigation of New Servo Drive Concept Utilizing Two Fixed Displacement Units. Int. J. Fluid Power Syst. 2014, 8, 1-9. [CrossRef]

10. Hagen, D.; Padovani, D.; Ebbesen, M.K. Study of a Self-Contained Electro-Hydraulic Cylinder Drive. In Proceedings of the 2018 Global Fluid Power Society Ph.D. Symposium (GFPS), Samara, Russia, 18-20 July 2018.

11. Michel, S.; Weber, J. Energy-Efficient Electrohydraulic Compact Drives for Low Power Applications. In Proceedings of the ASME/BATH 2012 Symposium on Fluid Power and Motion Control, Bath, UK, 12-14 September 2012; pp. 93-107.

12. Padovani, D.; Ketelsen, S.; Hagen, D.; Schmidt, L. A Self-Contained Electro-Hydraulic Cylinder with Passive Load-Holding Capability. Energies 2019, 12, 292. [CrossRef]

13. Jalayeri, E.; Imam, A.; Tomas, Z.; Sepehri, N. A throttle-less single-rod hydraulic cylinder positioning system: Design and experimental evaluation. Adv. Mech. Eng. 2015, 7, 1687814015583249. [CrossRef]

14. Weber, I.J.; Schneider, D.I.; Shabi, M.S.; Sitte, D.I.; Weber, D.I.; Willkomm, D.I.; Beck, D.I.; Fischer, D.I.; Ivantysyn, M.S.; Kolks, D.I.; et al. Novel System Architectures by Individual Drives. In Proceedings of the 10th International Fluid Power Conference, Dresden, Germany, 8-10 March 2016; pp. 29-62.

15. Ketelsen, S.; Padovani, D.; Andersen, T.; Ebbesen, M.; Schmidt, L. Classification and Review of Pump-Controlled Differential Cylinder Drives. Energies 2019, 12, 1293. [CrossRef]

16. Schmidt, L.; Ketelsen, S.; Brask, M.H.; Mortensen, K.A. A class of energy efficient self-contained electro-hydraulic drives with self-locking capability. Energies 2019, 12, 1866. [CrossRef]

17. Minav, T.A.; Laurila, L.I.E.; Pyrhönen, J.J. Analysis of electro-hydraulic lifting system's energy efficiency with direct electric drive pump control. Autom. Constr. 2013, 30, 144-150. [CrossRef]

18. Minav, T.A.; Sainio, P.; Pietola, M. Efficiency of Direct Driven Hydraulic Setup in Arctic Conditions. In Proceedings of the Fourteenth Scandinavian International Conference on Fluid Power, Tampere, Finland, 20-22 May 2015.

19. Schmidt, L.; Roemer, D.B.; Pedersen, H.C.; Andersen, T.O. Speed-Variable Switched Differential Pump System for Direct Operation of Hydraulic Cylinders. In Proceedings of the ASME/BATH Symposium on Fluid Power and Motion Control, Chicago, IL, USA, 12-14 October 2015.

20. Schneider, M.; Koch, O.; Weber, J. Green Wheel Loader-Improving Fuel Economy through Energy Efficient Drive and Control Concepts. In Proceedings of the 10th International Fluid Power Conference, Dresden, Germany, 8-10 March 2016; pp. 63-78. 
21. Schmidt, L.; Ketelsen, S.; Padovani, D.; Mortensen, K.A. Improving the Efficiency and Dynamic Properties of a Flow Control Unit in a Self-Locking Compact Electro-Hydraulic Cylinder Drive. In Proceedings of the ASME/Bath Symposium on Fluid Power and Motion Control, Longboat Key, FL, USA, 7-9 October 2019.

22. Michel, S.; Weber, J. Prediction of the Thermo-Energetic Behaviour of an Electrohydraulic Compact Drive. In Proceedings of the 10th International Fluid Power Conference, Dresden, Germany, 8-10 March 2016; pp. 219-234.

23. Minav, T.; Papini, L.; Pietola, M. A Thermal Analysis of Direct Driven Hydraulics. In Proceedings of the 10th International Fluid Power Conference, Dresden, Germany, 8-10 March 2016; pp. 235-248.

24. Karlén, N.; Minav, T.A.; Pietola, M. Investigation of Thermal Effects in Direct Driven Hydraulic System for Off-Road Machinery. In Proceedings of the 9th FPNI Ph.D. Symposium on Fluid Power, Florianópolis, Brazil, 26-28 October 2016.

25. Schmidt, L.; Groenkjaer, M.; Pedersen, H.C.; Andersen, T.O. Position Control of an Over-Actuated Direct Hydraulic Cylinder Drive. Control Eng. Pract. 2017, 64, 1-14. [CrossRef]

26. Ketelsen, S.; Schmidt, L.; Donkov, V.H.; Andersen, T.O. Energy saving potential in knuckle boom cranes using a novel pump controlled cylinder drive. Model. Identif. Control 2018, 39, 73-89. [CrossRef]

27. Hagen, D.; Padovani, D.; Choux, M. Enabling Energy Savings in Offshore Mechatronic Systems by using Self-Contained Cylinders. Model. Identif. Control 2019, 40, 89-108. [CrossRef]

28. Hagen, D.; Padovani, D.; Choux, M. A Comparison Study of a Novel Self-Contained Electro-Hydraulic Cylinder versus a Conventional Valve-Controlled Actuator-Part 1: Motion Control. Actuators 2019, in press.

29. Hagen, D.; Padovani, D.; Choux, M. Design and Implementation of Pressure Feedback for Load-Carrying Applications with Position Control. In Proceedings of the Sixteenth Scandinavian International Conference on Fluid Power, Tampere, Finland, 22-24 May 2019.

30. Ristic, M.; Wahler, M. Electrification of Hydraulics Opens New Ways for Intelligent Energy-Optimized Systems. In Proceedings of the 11th International Fluid Power Conference, Aachen, Germany, 19-21 March 2018.

(C) 2019 by the authors. Licensee MDPI, Basel, Switzerland. This article is an open access article distributed under the terms and conditions of the Creative Commons Attribution (CC BY) license (http://creativecommons.org/licenses/by/4.0/). 